\title{
PENGARUH SECONDARY AGING TREATMENT TERHADAP SIFAT MEKANIK DAN SURFACE GLOSSINESS PADA ALUMINIUM PADUAN 7003
}

\author{
Ramli $^{1}$ \\ ${ }^{1}$ Jurusan Teknik Mesin, Politeknik Manufaktur Negeri Bangka Belitung \\ Kawasan Industri Air Kantung, Sungailiat-Bangka, 33211 \\ Tel: 0717-93586, Fax: 0717-93585 \\ ramli.barmawi@yahoo.com
}

\begin{abstract}
As technology advances and the quality of life improves, there is a deep need that requires of aluminium alloy that bears high strength, high toughness, high surface glossiness, anti-corrosion, and high fatigue resistivity [2]. This study aims to investigate the effects of secondary aging treatment on the mechanical properties and Surface Glossiness of the 7003 aluminium alloy by using several equipment, including: confocal laser microscope, white light interferometer, gloss meter, micro Vickers hardness tester and tensile test machine. This research was conducted by experimental method by giving treatment on the aluminium alloy 7003 with some treatments, there are: aging treatment at $100^{\circ} \mathrm{C}$ for 5 hours and then secondary aging treatment at several different temperatures at $150^{\circ} \mathrm{C}, 175^{\circ} \mathrm{C}$ and $200^{\circ} \mathrm{C}$ for 9 hours respectively. Based on our experimental results, it obtained: After being aged at $100{ }^{\circ} \mathrm{C}$ for 5 hours and then secondary aged at $175^{\circ} \mathrm{C}$ for 9 hours, the 7003 aluminium alloy obtained excellent mechanical properties, which can achieve the industrial requirements of Yield strength $320 \mathrm{MPa}$ and Elongation 13\% for 3C mobile phone products. The 7003 aluminium alloy after being anodizing treated could obtain excellent Surface Glossiness and oxidation layer. The present aluminium alloy can achieve Surface Glossiness better than $1200 \mathrm{GU}$ and the thickness of oxidation layer exceed $10 \mu \mathrm{m}$, which were suitable for 3C industrial applications [3-4].
\end{abstract}

Keywords: 7003 aluminium alloy, secondary aging, mechanical properties, surface glossiness

\begin{abstract}
Abstrak
Seiring kemajuan teknologi dan kualitas hidup meningkat, ada kebutuhan mendalam yang mensyaratkan aluminium paduan memiliki sifat kekuatan tinggi, ketangguhan tinggi, kekilauan permukaan tinggi, anti korosi, dan ketahanan terhadap kelelahan yang tinggi [2]. Penelitian ini bertujuan untuk menginvestigasi pengaruh secondary aging treatment terhadap sifat mekanik dan tingkat kekilauan permukaan dari aluminium paduan 7003 dengan menggunakan beberapa peralatan, diantaranya : confocal laser microscope, white light interferometer, gloss meter, mesin uji kekerasan micro vickers dan mesin uji tarik. Penelitian ini dilakukan dengan metode eksperimental dengan memberikan perlakuan pada aluminium paduan 7003 dengan beberapa perlakuan, yaitu aging treatment pada suhu $100^{\circ} \mathrm{C}$ selama 5 jam dilanjutkan dengan secondary aging treatment pada suhu yang berbeda yaitu pada suhu $150^{\circ} \mathrm{C}, 175^{\circ} \mathrm{C}$ dan $200^{\circ} \mathrm{C}$ masing-masing selama 9 jam. Berdasarkan hasil percobaan, diperoleh : Setelah dilakukan aging treatment pada suhu $100^{\circ} \mathrm{C}$ selama 5 jam dan kemudian dilanjutkan dengan secondary aging treatment pada suhu $175^{\circ} \mathrm{C}$ selama 9 jam, diperoleh sifat mekanik dari aluminium paduan 7003 yang sangat baik, yang dapat memenuhi persyaratan industri 3C (Computer, Communication and Consumer Electrocic) dengan yield strength $320 \mathrm{MPa}$ dan elongasi 13\% untuk produk ponsel; Aluminium paduan 7003 setelah di anodisasi mendapatkan tingkat kekilauan permukaan (surface glossiness) lebih dari $1200 \mathrm{GU}$ dan ketebalan lapisan oksidasi melebihi 10 $\mu \mathrm{m}$ sehingga dapat diaplikasikan untuk produk ponsel pada perusahaan 3C [3-4].
\end{abstract}

Kata kunci: Aluminium paduan 7003, secondary aging treatment, sifat mekanik, kekilauan permukaan.

Pengaruh Secondary Aging Treatment Terhadap Sifat Mekanik dan Surface Glossiness pada Alumunium Panduan 2003 (Ramli) 


\section{PENDAHULUAN}

Aluminium paduan memiliki sifat yang sangat baik seperti ringan, kekuatan tinggi, anti korosi, mudah dibentuk, mudah diproses, konduktivitas listrik tinggi, non-magnetisme, keragaman warna permukaan, yang membuat aluminium paduan menjadi material logam penting dengan aplikasi yang luas di masa mendatang [1]. Namun demikian, seiring dengan kemajuan teknologi dan kualitas hidup meningkat, ada kebutuhan mendalam yang mensyaratkan aluminium paduan memiliki sifat kekuatan tinggi, ketangguhan tinggi, Surface Glossiness tinggi, anti korosi, dan ketahanan terhadap kelelahan yang tinggi [2].

Melalui pembahasan gagasan tentang desain aluminium paduan, kontrol parameter proses ekstrusi, proses perlakuan panas aluminium paduan, dan proses anodisasi pada permukaan, yang bertujuan untuk mengembangkan jenis baru dari aluminium paduan komersial yang memiliki nilai tambah yang tinggi, kekuatan tinggi dan kualitas permukaan tinggi sehingga cocok untuk industri 3C [34], peralatan atletik, industri kedirgantaraan dan industri suku cadang seperti silinder mobil dan silinder sepeda motor [5]. Oleh karena itu, penelitian ini selain fokus pada efek parameter perlakuan panas serta parameter proses anodisasi permukaan yang optimal terhadap sifat mekanik dari aluminium paduan 7003, pengaruh terhadap kualitas kekilauan permukaan juga diinvestigasi.

\section{METODE PENELITIAN}

Metode yang digunakan dalam penelitian ini yaitu metode eksperimental untuk menyelidiki hubungan sebab akibat dengan memberikan satu atau lebih kondisi perlakuan kepada satu atau lebih eksperimental. Perumusan masalah pada penelitian ini bersumber dari persyaratan material yang dibutuhkan oleh industri-industri $3 \mathrm{C}$ yang mensyaratkan material harus memiliki Yield Strength $320 \mathrm{MPa}$ dan Elongasi 13\% untuk produk ponsel. Oleh karena itu, pada penelitian ini dilakukan beberapa percobaan dengan melakukan beberapa treatment terhadap material aluminium paduan 7003 agar material tersebut dapat memenuhi persyaratan yang telah ditentukan.

Untuk menyelesaikan penelitian ini digunakan alur flow chart kegiatan sebagai pedoman dalam menentukan tindakan sehingga lebih terarah. Gambar 1. menunjukkan metodologi penelitian yang digunakan.

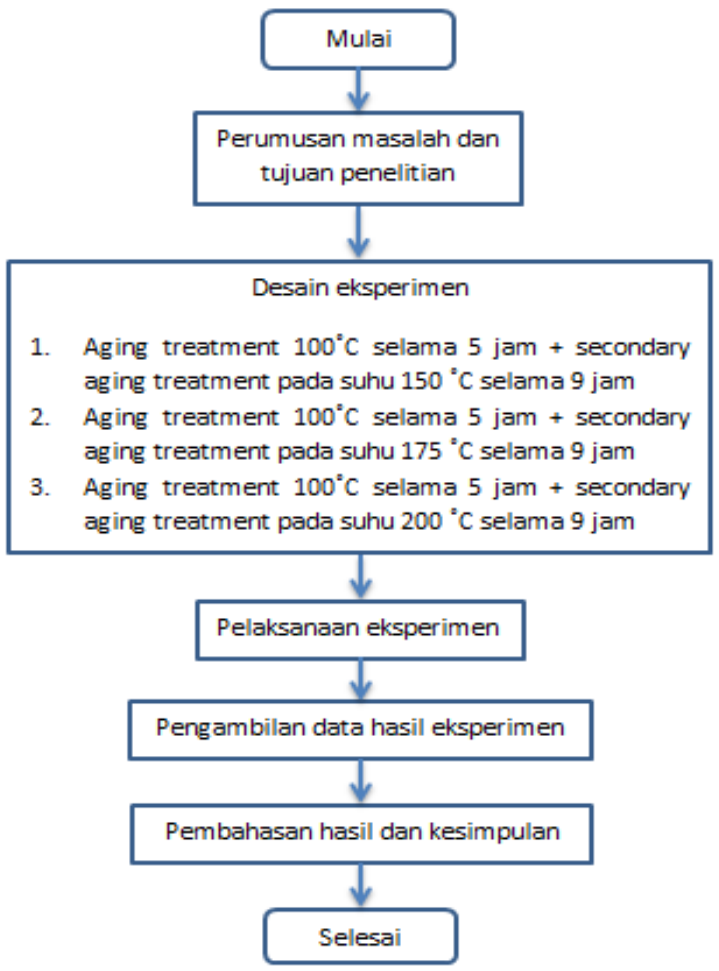

Gambar 1. Flow chart Metodologi Penelitian yang digunakan. 


\subsection{Rancangan Eksperimen}

Eksperimen ini merupakan proses perlakuan panas (heat treatment) pada aluminium paduan 7003 menggunakan proses aging treatment pada temperatur dan waktu yang sama dan dilanjutkan dengan proses secondary aging treatment dengan waktu yang sama pada temperatur yang berdeda. Percobaan yang dilakukan terdiri dari tiga macam percobaan kemudian dilakukan beberapa pengujian yang meliputi pengujian kekerasan, pengukuran ketebalan lapisan oksidasi, pengukuran glossiness surface, tensile strength, yield strength dan elongasi untuk mendapatkan data hasil dari eksperimen tersebut.

Percobaan pertama dengan cara melakukan aging treatment pada suhu $100^{\circ} \mathrm{C}$ selama 5 jam, kemudian dilanjutkan dengan secondary aging treatment pada suhu $150^{\circ} \mathrm{C}$ selama 9 jam. Percobaan kedua dengan cara melakukan aging treatment pada suhu $100^{\circ} \mathrm{C}$ selama 5 jam, kemudian dilanjutkan dengan secondary aging treatment pada suhu $175^{\circ} \mathrm{C}$ selama 9 jam dan percobaan ketiga dengan melakukan aging treatment pada suhu $100^{\circ} \mathrm{C}$ selama 5 jam, kemudian dilanjutkan dengan secondary aging treatment pada suhu $200^{\circ} \mathrm{C}$ selama 9 jam.

\section{HASIL DAN PEMBAHASAN}

Berdasarkan hasil dari ketiga percobaan yang dilakukan, didapatkan nilai kekerasan (hardness) yang ditunjukkan pada Gambar 2.

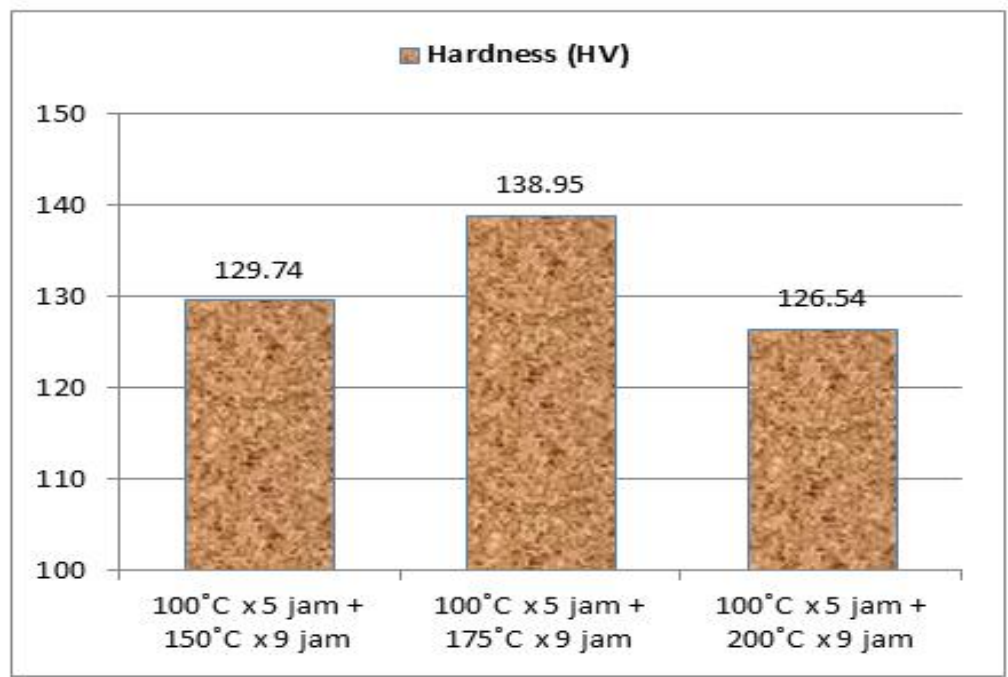

Gambar 2. Diagram Hasil Uji Kekerasan Micro-Vickers

Aluminium paduan 7003 setelah dilakukan secondary aging treatment selama 9 jam pada suhu $175^{\circ} \mathrm{C}$ didapatkan nilai kekerasan $138.95 \mathrm{HV}$, sedangkan pada suhu $150^{\circ} \mathrm{C}$ dan $200^{\circ} \mathrm{C}$ didapatkan nilai kekerasan yang lebih rendah, dimana nilai kekerasan dari proses secondary aging treatment pada suhu $150^{\circ} \mathrm{C}$ sebesar $129.74 \mathrm{HV}$ sedikit lebih besar dibandingkan dengan pada suhu $200^{\circ} \mathrm{C}$.

Hasil percobaan menunjukkan bahwa dengan melakukan secondary aging treatment pada suhu $175^{\circ} \mathrm{C}$ selama 9 jam menghasilkan kekuatan Tarik (Tensile Strength) yang lebih tinggi yaitu $388.24 \mathrm{MPa}$ dibandingkan dengan secondary aging treatment pada suhu $150^{\circ} \mathrm{C}$ dan $200^{\circ} \mathrm{C}$ yang menghasilkan Kekuatan Tarik masing-masing sebesar 369.75 MPa dan 374.79 MPa. Berbeda dengan nilai kekerasan yang dihasilkan, pada hasil uji Kekuatan Tarik ini, aluminium paduan 7003 setelah dilakukan secondary aging treatment pada suhu $200^{\circ} \mathrm{C}$ menghasilkan Kekuatan Tarik sedikit lebih besar dibandingkan dengan secondary aging pada suhu $150^{\circ} \mathrm{C}$. Secara grafik, hasil uji Kekuatan Tarik (Tensile Strength) dari ketiga percobaan dapat dilihat pada Gambar 3. 


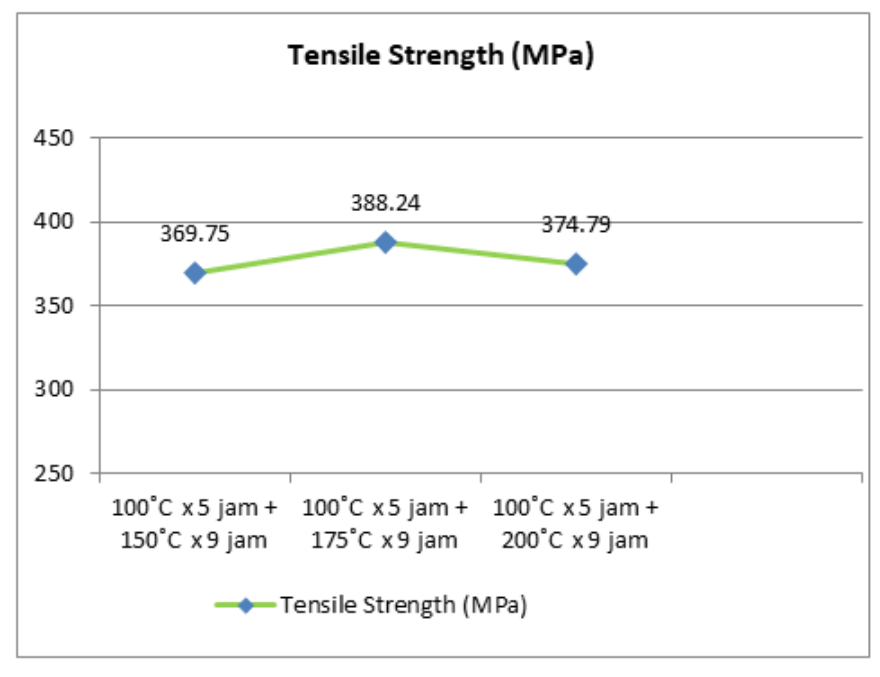

Gambar 3. Grafik Hasil Uji Kekuatan Tarik (Tensile Strength)

Pada hasil pengujian kekuatan mulur (Yield Strength) dan Elongasi (Elongation) juga, dengan melakukan proses secondary aging treatment pada suhu $175^{\circ} \mathrm{C}$ akan menghasilkan Tensile Strength dan Elongasi yang lebih tinggi dibandingkan pada suhu $200^{\circ} \mathrm{C}$ dan $150^{\circ} \mathrm{C}$. Kekuatan Mulur (Yield strength) pada suhu $175^{\circ} \mathrm{C}$ adalah sebesar $364.15 \mathrm{MPa}$ dan elongasi sebesar 22.33\% sehingga dapat memenuhi persyaratan industri 3C (Computer, Communication and Consumer Electrocic), dimana persyaratan produk perusahaan 3C yaitu Yield Strength 320 MPa dan Elongasi 13\% untuk produk ponsel [3-4]. Dari hasil percobaan mengindikasikan bahwa semakin tinggi Yield Strength maka Elongation juga semakin tinggi. Hal ini sesuai dengan korelasi antara Yield Strength dan Elongation berbanding lurus [5]. Nilai Tensile Strength dan Elongation dari ketiga percobaan ditunjukkan pada Gambar 4.

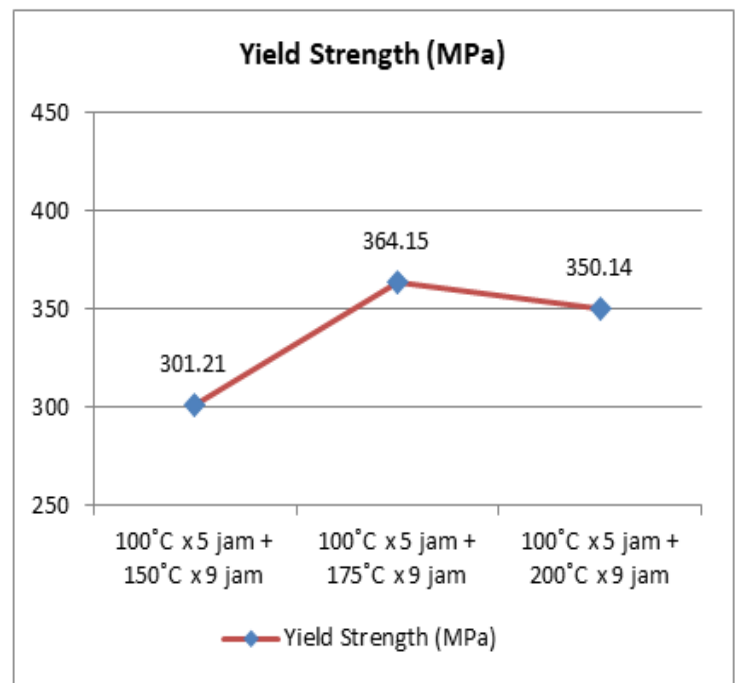

(a)

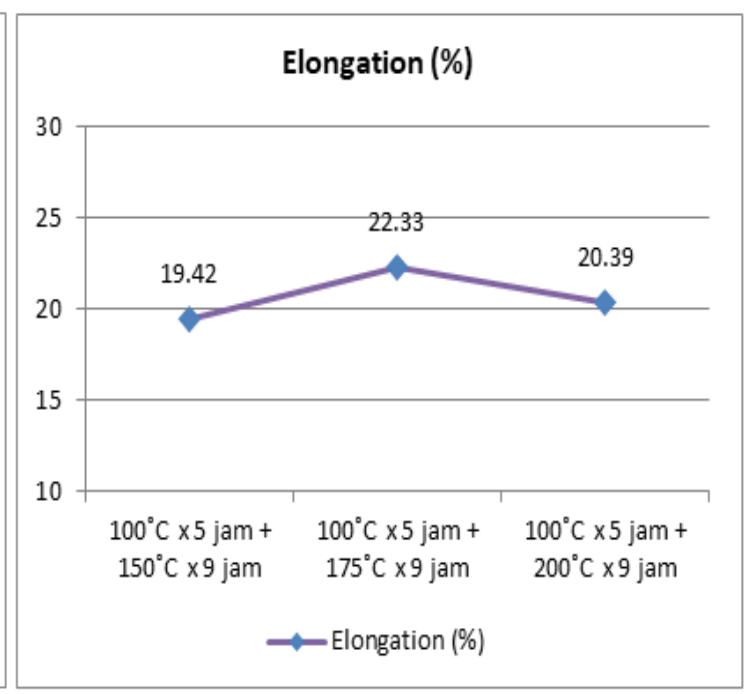

(b)

Gambar 4. Hasil Uji Kekuatan Mulur (Yield Strength) (a) dan Hasil Elongasi (Elongation) dari ketiga percobaan.

Grafik hasil pengukuran ketebalan lapisan oksidasi (Thickness of Oxidation Layer) dan Surface Glossiness dari ketiga percobaan menunjukkan ketebalan lapisan oksidasi dari aluminium paduan 7003 setelah dilakukan proses secondary aging treatment pada suhu $150^{\circ} \mathrm{C}, 175^{\circ} \mathrm{C}$ dan $200^{\circ} \mathrm{C}$ masing-masing sebesar $10.2 \mu \mathrm{m}, 10.3 \mu \mathrm{m}$, dan $10.4 \mu \mathrm{m}$. Sedangkan tingkat Surface Glossiness masing-masing sebesar 
1289 GU, 1262 GU, dan 1229 GU. Hal ini mengindikasikan bahwa terjadi peningkatan ketebalan lapisan oksidasi seiring dengan meningkatnya suhu.

Pada setiap kenaikan suhu sebesar $25^{\circ} \mathrm{C}$ terjadi peningkatan rata-rata ketebalan lapisan oksidasi sebesar $0.1 \mu \mathrm{m}$. Sedangkan terhadap Surface Glossiness terjadi penurunan dengan meningkatnya suhu pada secondary aging treatment, dimana setiap kenaikan suhu sebesar $25^{\circ} \mathrm{C}$ terjadi rata-rata penurunan sebesar $30 \mathrm{GU}$.

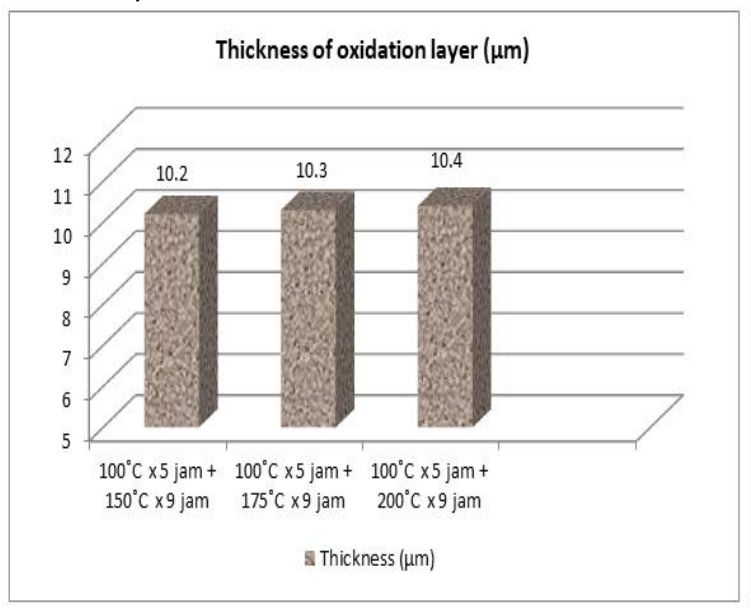

(a)

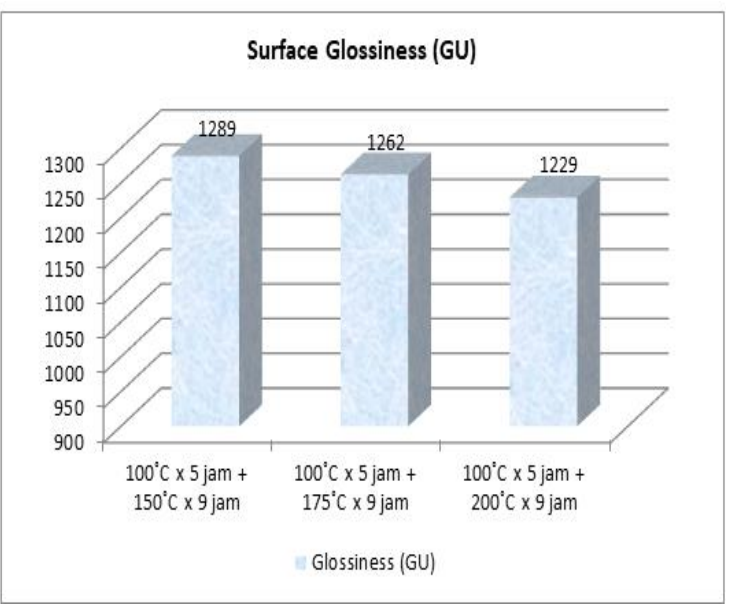

(b)

Gambar 5. Hasil Pengukuran Thickness of Oxidation Layer (a) dan Hasil Pengukuran Surface Glossiness dari ketiga percobaan.

\section{SIMPULAN}

Dari hasil penelitian ini, dengan melakukan proses secondary aging treatment pada aluminium paduan 7003 dapat disimpulkan bahwa :

1. Sifat mekanik yang paling tinggi didapatkan pada suhu $175^{\circ} \mathrm{C}$.

2. Setiap peningkatan suhu sebesar $25^{\circ} \mathrm{C}$ pada proses secondary aging treatment terjadi peningkatan ketebalan lapisan oksidasi rata-rata sebesar $0.1 \mu \mathrm{m}$ dan penurunan Surface Glossiness rata-rata sebesar $30 \mathrm{GU}$.

3. Semakin tinggi ketebalan lapisan oksidasi maka Surface Glossiness semakin menurun.

4. Dengan suhu $175^{\circ} \mathrm{C}$ pada aluminium paduan 7003 didapatkan sifat mekanik dan Surface Glossiness yang memenuhi persayaratan material produk 3C.

\section{DAFTAR PUSTAKA}

[1]. K. K. Chawla, A. H. Esmaeili, A. K. Datye, and A. K. Vasudevan, "Effect of homogeneous/heterogeneous precipitation on aging behavior of SiCp Al 2014 composite," Scripta Metallurgica et Materiala, vol. 25, no. 6, pp. 1315-1319, 1991.

[2]. S. L. Dong, J. F. Mao, D. Z. Yang, Y. X. Cui, and L. T. Jiang, "Age-hardening behavior of a SiCw/AlLi-Cu-Mg-Zr composite," Materials Science and Engineering A, vol. 327, no. 2, pp. 213-223, 2002.

[3]. A. Karaaslan, I. Kaya and H. Atapek, "Effect of Aging Temperature and of Retrogression Treatment Time on the Microstructure and Mechanical Properties of Alloy AA 7075," Metal Science and Heat Treatment, vol.49, no.9-10, pp. 443-447, 2007.

[4]. M. M. Tash, S. Alkahtani, "Aging and Mechanical Behavior of Be-Treated 7075 Aluminum Alloys," World Academy of Science, Engineering and Technology International Journal of Materials and Metallurgical Engineering Vol.8, No.3, 2014.

[5]. D.A.P. Reis, A.A. Couto, N.I. Domingues Jr., A.C.O. Hirschmann, S. Zepka, C. Moura Neto, "Effect of Artificial Aging on the Mechanical Properties of an Aerospace Aluminum Alloy 2024," Defect and Diffusion Forum Vols. 326-328, pp. 193-198, 2012. 